\title{
High-resolution meteorological forcing data for hydrological modelling and climate change impact analysis in the Mackenzie River Basin
}

\author{
Zilefac Elvis Asong ${ }^{1}$, Mohamed Ezzat Elshamy ${ }^{1}$, Daniel Princz ${ }^{1}$, Howard Simon Wheater ${ }^{1}$, \\ John Willard Pomeroy ${ }^{1,2}$, Alain Pietroniro ${ }^{1,2,3}$, and Alex Cannon ${ }^{4}$ \\ ${ }^{1}$ Global Institute for Water Security, University of Saskatchewan, 11 Innovation Blvd, \\ Saskatoon, SK, S7N 3H5, Canada \\ ${ }^{2}$ Centre for Hydrology, University of Saskatchewan, 121 Research Drive, Saskatoon, SK, S7N 1K2, Canada \\ ${ }^{3}$ Environment and Climate Change Canada, 11 Innovation Blvd, Saskatoon, SK, S7N 3H5, Canada \\ ${ }^{4}$ Climate Research Division, Environment and Climate Change Canada, BC V8W 2Y2, Victoria, Canada
}

Correspondence: Zilefac Elvis Asong (elvis.asong@usask.ca)

Received: 14 June 2019 - Discussion started: 31 July 2019

Revised: 20 January 2020 - Accepted: 3 February 2020 - Published: 19 March 2020

\begin{abstract}
Cold region hydrology is very sensitive to the impacts of climate warming. Impacts of warming over recent decades in western Canada include glacier retreat, permafrost thaw, and changing patterns of precipitation, with an increased proportion of winter precipitation falling as rainfall and shorter durations of snow cover, as well as consequent changes in flow regimes. Future warming is expected to continue along these lines. Physically realistic and sophisticated hydrological models driven by reliable climate forcing can provide the capability to assess hydrological responses to climate change. However, the provision of reliable forcing data remains problematic, particularly in data-sparse regions. Hydrological processes in cold regions involve complex phase changes and so are very sensitive to small biases in the driving meteorology, particularly in temperature and precipitation, including precipitation phase. Cold regions often have sparse surface observations, particularly at high elevations that generate a large amount of runoff. This paper aims to provide an improved set of forcing data for large-scale hydrological models for climate change impact assessment. The best available gridded data in Canada are from the high-resolution forecasts of the Global Environmental Multiscale (GEM) atmospheric model and outputs of the Canadian Precipitation Analysis (CaPA), but these datasets have a short historical record. The EU WATCH ERA-Interim reanalysis (WFDEI) has a longer historical record but has often been found to be biased relative to observations over Canada. The aim of this study, therefore, is to blend the strengths of both datasets (GEM-CaPA and WFDEI) to produce a less-biased long-record product (WFDEI-GEM-CaPA) for hydrological modelling and climate change impact assessment over the Mackenzie River Basin. First, a multivariate generalization of the quantile mapping technique was implemented to bias-correct WFDEI against GEM-CaPA at $3 \mathrm{~h} \times 0.125^{\circ}$ resolution during the 2005-2016 overlap period, followed by a hindcast of WFDEIGEM-CaPA from 1979. The derived WFDEI-GEM-CaPA data are validated against station observations as a preliminary step to assess their added value. This product is then used to bias-correct climate projections from the Canadian Centre for Climate Modelling and Analysis Canadian Regional Climate Model (CanRCM4) between 1950 and 2100 under RCP8.5, and an analysis of the datasets shows that the biases in the original WFDEI product have been removed and the climate change signals in CanRCM4 are preserved. The resulting biascorrected datasets are a consistent set of historical and climate projection data suitable for large-scale modelling and future climate scenario analysis. The final historical product (WFDEI-GEM-CaPA, 1979-2016) is freely available at the Federated Research Data Repository at https://doi.org/10.20383/101.0111 (Asong et al., 2018), while the original and corrected CanRCM4 data are available at https://doi.org/10.20383/101.0162 (Asong et al., 2019).
\end{abstract}




\section{Introduction}

Accurate and reliable weather and climate information at the basin scale is in increasingly high demand by policymakers, scientists, and other stakeholders for many purposes including water resources management (Barnett et al., 2005), infrastructure planning (Brody et al., 2007), and ecosystem modelling (IPCC, 2013). Specifically, the potential impacts of a warming climate on water availability in snowdominated high-latitude regions continue to be a serious concern given that over the past several decades these regions have experienced some of the most rapid warming on Earth (Demaria et al., 2016; Diffenbaugh et al., 2012; Islam et al., 2017; Martin and Etchevers, 2005; Stocker et al., 2013). The ongoing science suggests that these warming trends are resulting in the intensification of the hydrologic cycle, leading to significant recent observed changes in the hydro-climatic regimes of major river basins in Canada and globally (Coopersmith et al., 2014; DeBeer et al., 2016; Dumanski et al., 2015). Changes in the timing and magnitude of river discharge (Dibike et al., 2016); shifts in extreme temperature and precipitation regimes (Asong et al., 2016b; Vincent et al., 2015); and changes in snow, ice, and permafrost regimes are anticipated (IPCC, 2013). Substantial evidence also indicates that the long-held notion of stationarity of hydrological processes is becoming invalid in a changing climate. As pointed out by Milly et al. (2008), this loss of stationarity means that there will be an increase in the likelihood and frequency of extreme weather and climate events, including floods and droughts. What is particularly troubling is that these impacted regions typically have extremely low density of weather and climate observations, making any attribution and climate impact analysis on water resources difficult.

It is well understood that water resources in most watersheds north of $30^{\circ} \mathrm{N}$ are heavily dependent on natural water storage provided by snowpacks and glaciers, with water accumulated in the solid phase during the cold season and released in the liquid phase during warm events and the warm season. Particularly, the Canadian Rocky Mountains, the hydrological apex of North America with headwater streams flowing to the Arctic, Atlantic, and Pacific oceans, constitute an integral part of the global hydrological cycle (Fang et al., 2013). Flows in these high-elevation headwaters depend heavily on meltwater from snowpacks and glaciers. However, given that it is characterized by a highly varying cold region hydro-climate, studies indicate that it is in these highelevation regions where climate variability and change are expected to be most pronounced in terms of their impacts on water supply (Beniston, 2003; Kane et al., 1991; Prowse and Beltaos, 2002; Woo and Pomeroy, 2011). More physically realistic and sophisticated hydrological models driven by reliable climate forcing information can enhance our ability to assess short- and long-term regional hydrologic responses to increasing variability and uncertainty in hydro-climatic conditions in a changing climate. Nonetheless, hydrological processes in cold regions involve complex phase changes and so are very sensitive to small biases in the driving meteorology, particularly in temperature and precipitation.

As described earlier, cold regions often have sparse surface observations, particularly at the high-elevation and highlatitude regions that could potentially generate a major amount of runoff. The effects of mountain topography and high latitudes are currently not well reflected in the observational record. Ground-based measurements (e.g. gauges) are limited especially over the Canadian Rocky Mountains and suffer from inaccuracies associated with cold climate processes (Asong et al., 2017; Wang and Lin, 2015; Wong et al., 2017). The advent and use of weather radar systems have addressed some of the shortcomings of gauge coverage, at least where radar systems exists. Unfortunately, in Canada, for example, the spatial coverage of weather radar systems is limited to the southern (south of $55^{\circ} \mathrm{N}$ ) part of the country (Fortin et al., 2015b). Recently, improved satellite products have emerged, such as the Global Precipitation Measurement (GPM) mission that provides meteorological information at fine spatio-temporal resolutions and regular intervals. However, the GPM is still at an early stage of development and only covers the region south of $60^{\circ} \mathrm{N}$ (Asong et al., 2017; Hou et al., 2014).

The capability of the current generation of Earth system models (ESMs) to represent meteorological forcing variables is therefore of major interest for hydrological climate change impact studies in cold region watersheds. Despite commendable progress being made, raw outputs from regional and global ESMs still have large differences between models and from the limited observational reference meteorology, due partly to spatial-scale mismatches and systematic biases (Taylor et al., 2012). Therefore, ESM outputs are often downscaled and biases are adjusted statistically before being used in hydrological simulations (Asong et al., 2016b; Chen et al., 2013, 2018; Gudmundsson et al., 2012). Recent research has demonstrated that bias correction, including adjustment of the dependence between driving variables, can lead to more realistic hydrological simulations in cold region watersheds where the response of the system is sensitive to accumulation and melt of snow and ice (Meyer et al., 2019).

Apart from the uncertainty due to the many empirical statistical techniques which have been developed to postprocess ESM outputs (Maraun, 2016), the quality and length of the reference observational dataset for bias correction remains a major issue (Reiter et al., 2016; Schoetter et al., 2012; Sippel et al., 2016). In Canada and other regions of North America, regional gridded datasets such as the combined Global Environmental Multiscale (GEM) atmospheric model forecasts (Yeh et al., 2002) and the Canadian Precipitation Analysis (CaPA; Mahfouf et al., 2007) have been 
found to perform comparably to ground observations, both statistically and hydrologically (Alavi et al., 2016; Boluwade et al., 2018; Eum et al., 2014; Fortin et al., 2015a; Gbambie et al., 2017; Wong et al., 2017). However, the duration of GEM-CaPA is too short to be used to directly correct ESM climate due to unsynchronized internal variability - the recommended minimum record length for bias correction is 30 years (Maraun, 2016; Maraun et al., 2017). Other gridded products such as the EU WATCH ERA-Interim reanalysis (WFDEI; Weedon et al., 2014) and Princeton (Sheffield et al., 2006) have a longer historical record but have been found to be biased relative to observations over Canada (Wong et al., 2017) and the United States (Behnke et al., 2016; Sapiano and Arkin, 2009). However, the WFDEI reanalysis has been found to outperform other long-record gridded products (Chadburn et al., 2015; Park et al., 2016; Wong et al., 2017).

Because of the sparse observational network, few gridded climate datasets exist that contain the necessary meteorological variables to drive physically based land surface models at sub-daily temporal resolution north of $55^{\circ} \mathrm{N}$ in North America. Because the combination of the GEM and CaPA datasets has been shown to perform relatively well in these regions, the intent here is to use these datasets to bias-correct the WFDEI dataset, which contains a sufficient length of record for bias-correcting climate projection datasets. Aside from its short record length, a limitation of the GEM-CaPA dataset for wider use for hydrological models is that the wind, temperature, and humidity variables are available only at the $0.995 \operatorname{sigma}(\sigma)$ level (approximately $40 \mathrm{~m}$, varying in time and space; herein referred to as the $40 \mathrm{~m}$ level) across the full length of record. The WFDEI dataset contains these variables at the surface level, which is more typically used by hydrological models. Therefore, the bias correction effectively modifies the source surface level data to reproduce the climate found at the $40 \mathrm{~m}$ level of the reference dataset (GEMCaPA). Many regional and large-scale land surface hydrological models are capable of using climate data at this atmospheric level. Thus, no effort is made to interpolate the product back to surface level (although this could be done if needed). In addition, the bias-corrected dataset at an effective $40 \mathrm{~m}$ level can then be used to bias-correct these same fields from the CanRCM4 dataset, which are at the same $0.995 \sigma$ level as in the reference dataset (GEM-CaPA). The analysis results in a bias-corrected set of historical and projected climate data that is consistent in time and considers the regional topography and climate effects of GEM and CaPA and is suitable to drive large-scale simulations of distributed hydrological models for assessing climate change impacts in data-sparse regions.

The aim of this study, therefore, is to combine the strengths of both datasets (GEM-CaPA and WFDEI) to produce a less-biased long-record product (WFDEI-GEM-CaPA) using a multistage bias correction framework. First, a multivariate generalization of the quantile mapping technique was implemented to bias-correct WFDEI against GEM-CaPA at
$3 \mathrm{~h} \times 0.125^{\circ}$ resolution during the 2005-2016 period, followed by a hindcast of WFDEI-GEM-CaPA from 1979. Subsequently, a 15-member initial condition ensemble of the CanESM2 ESM (historical followed by RCP8.5 scenario), which has been dynamically downscaled at $0.44^{\circ}(50 \mathrm{~km})$ resolution using the fourth-generation Canadian Regional Climate Model (CanRCM4), is sourced from the Canadian Centre for Climate Modelling and Analysis. A multivariate bias correction algorithm is applied to the CanRCM4 outputs (1950-2100) to adjust the data against WFDEI-GEMCaPA. The bias-corrected products are important for developing distributed hydrological models as well as for assessing climate change impacts over the Mackenzie River Basin (MRB), which constitutes a test bed for the Changing Cold regions Network (CCRN) project's large-scale hydrological modelling strategy and is the case study for the current analysis.

\section{Methodology}

\subsection{Study area}

The study area is the Mackenzie River Basin, which is the largest river basin in Canada and the largest river draining from North America to the Arctic Ocean (Fig. 1). It drains an area of about 1.8 million $\mathrm{km}^{2}$ and discharges more than $300 \mathrm{~km}^{3}$ of freshwater to the Beaufort Sea in the Arctic each year. The basin drains parts of British Columbia, Alberta, Saskatchewan, the Northwest Territories, and the Yukon territory in northwestern Canada. The western tributaries are relatively steep as they originate from the Canadian Rocky Mountains, while the eastern tributaries have milder topography with several large lakes, thousands of interconnected small lakes, fens, and bogs. The general vegetation ranges widely between alpine, boreal, and tundra landscapes. Climatic conditions are also quite variable and can be generally classified as cold-temperate, mountain, subarctic, and arctic zones, with about $75 \%$ of the basin underlain by continuous and discontinuous permafrost.

\subsection{Data sources}

\subsubsection{Gridded GEM-CaPA product}

Hourly archived forecast data from the GEM model were acquired from Environment and Climate Change Canada (http://collaboration.cmc.ec.gc.ca/cmc/cmoi/product_guide/ submenus/rdps_e.html, last access: 28 September 2018). The fields include downward incoming solar radiation; downward incoming longwave radiation and pressure at the surface; and specific humidity, air temperature, and wind speed at approximately $40 \mathrm{~m}$ above ground surface. The $40 \mathrm{~m}$ level was used because surface level variables at $1.0 \sigma$ (approximately at $2 \mathrm{~m}$ for temperature and humidity, and $10 \mathrm{~m}$ for wind speed) are only available in the archive from 2010 onward. The GEM data are at approximately 


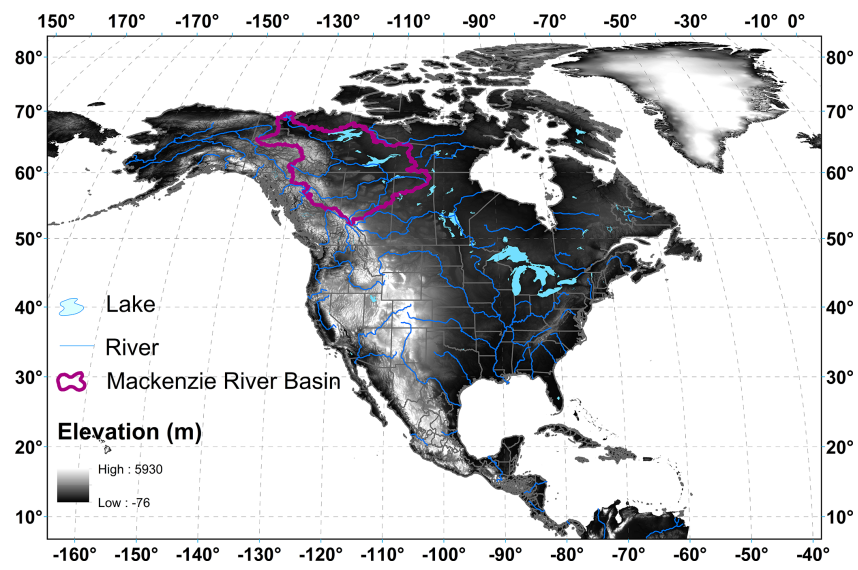

Figure 1. Location of the Mackenzie River Basin in North America. Digital elevation data come from GTOPO30 - 30 arcsec digital elevation data for the globe (https://www.arcgis.com/home/item. html?id=5771199a57cc4c29ad9791022acd7f74; last access: February 2018).

$24 \mathrm{~km}$ spatial resolution from October 2001, approximately $15 \mathrm{~km}$ from June 2004, and approximately $10 \mathrm{~km}$ resolution from November 2012, and they are provided on a rotated latitude-longitude grid in Environment and Climate Change Canada (ECCC) standard file format. The archived data are of former operational forecasts and contain model outputs from versions of GEM prior to 2.0.0 through 5.0.0.

Six-hourly total precipitation data from the complementary CaPA product (http://collaboration.cmc.ec.gc.ca/cmc/ cmoi/product_guide/submenus/capa_e.html, last access: 28 September 2018) were also acquired. The analysis incorporates observed precipitation from meteorological weather stations, and more recently from radar, into the precipitation field from GEM. The CaPA data are approximately $10 \mathrm{~km}$ resolution from January 2002, also on a rotated latitudelongitude grid in ECCC standard file format. The data contain reanalysis outputs from CaPA 2.4b8 from 2002 to 2012 and of former operational analyses from versions of CaPA 2.3.0 through 4.0.0 from November 2012 onward.

The variables from GEM and CaPA were spatially interpolated and reprojected to a regular latitude-longitude grid at $0.125^{\circ}$ resolution. For data from GEM, the interpolation was done using a bilinear algorithm, while data from $\mathrm{CaPA}$ were interpolated using nearest neighbour (Schulzweida et al., 2004). Where necessary, the GEM fields were converted to SI units, and CaPA was converted to a precipitation rate in SI units for better compatibility with some hydrological models.

\subsubsection{Gridded WFDEl product}

The gridded WFDEI meteorological forcing data have a global $0.5^{\circ}$ spatial resolution and $3 \mathrm{~h}$ time step covering the period 1979-2016 (http://www.eu-watch.org/data availability, last access: 25 July 2018). Weedon et al. (2014) used the ERA-Interim surface meteorology data as baseline information to derive the WFDEI product. Firstly, ERAInterim data were interpolated at $0.5^{\circ}$ spatial resolution to match the land-sea mask defined by the Climatic Research Unit (CRU) of the University of East Anglia, Norwich, England. Subsequently, corrections for elevation and monthly bias of climate trends in the ERA-Interim fields were applied to the interpolated data. The WFDEI data have two sets of precipitation data: the Global Precipitation Climatology Centre product (GPCC) and CRU Time Series version 3.1 (CRU TS3.1). Thus, two variants of the WFDEI product are available - WFDEI-GPCC and WFDEI-CRU. The WFDEI-CRU dataset was used here because it goes up to 2016, whilst the WFDEI-GPCC had only been updated until 2013 at the time of our analysis.

\subsubsection{Station observations}

To evaluate the added value of bias-correcting WFDEI against GEM-CaPA, in situ hourly precipitation, temperature, surface pressure, relative humidity, and wind speed at 773 stations located across the MRB were initially considered (Fig. 2). This station network is maintained by Environment and Climate Change Canada (ECCC) (http://climate. weather.gc.ca/historical_data/search_historic_data_e.html, last access: 17 December 2019) and includes some duplicate stations (stations at the same location but having different IDs). Total daily precipitation and average daily temperature are found in daily data files, while surface pressure, relative humidity, and wind speed are only found in hourly files. Unfortunately, radiation data are not available at any of those stations. The data were extracted for the period from 1 January 2005 to 31 December 2016, and hourly data were averaged to the daily time step. This reduced the number of stations to 364 . Out of these 364 stations, only 10 were found to have less than $10 \%$ missing data (calculated at the daily timescale after aggregating/averaging the data) for all studied variables concurrently over the 2005-2016 period and were retained for further consideration. Precipitation and surface pressure are the only two surface variables in all datasets (gridded and stations). Due to differences in heights between gridded variables of GEM-CaPA and WFDEI-GEM-CaPA datasets for air temperature, humidity, and wind speed (see Sects. 2.2.1 and 3.1) and the ECCC station data, we expect deviations. Nevertheless, the comparisons are still informative. Relative humidity observations were converted to specific humidity to be comparable to gridded datasets using concurrent station temperature and surface pressure data at those stations, which reduced the record completeness further but was still within $90 \%$ for the 10 selected stations. Table 1 provides additional information for the 10 stations retained for further analysis, which are highlighted in Fig. 2. This dataset is hereafter referred to as ECCC-S (S for stations). Table S1 in the Supplement 


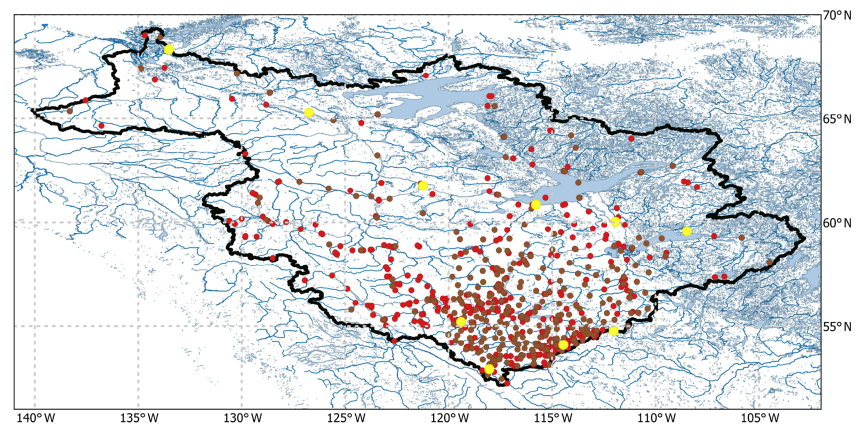

Figure 2. Spatial distribution of the initial 773 ground-based precipitation gauges (all dots) over the study area. Only 364 of these have records during the period 2005-2016 (brown and yellow dots). Data screening for missing values (10\% threshold concurrently applied for all variables) during the 2005-2016 period resulted in 10 of these stations (yellow dots) being retained for validation of gridded datasets. Blue lines indicate river network sourced from: https://open.canada.ca/data/en/dataset/ 16e8a362-d8be-53b7-acb8-e3f9c5cd54ef (last access: December 2019).

provides a similar listing to Table 1 but for all 364 stations with records during the 2005-2016 period.

\subsubsection{Climate model outputs}

The historical and future climate simulations utilized in this study are part of the CanRCM4 large ensemble, which consists of 50 members and is downscaled at horizontal spatial resolutions of $0.44^{\circ}(\sim 50 \mathrm{~km})$. These CanRCM4 simulations had been produced initially by the Canadian Sea Ice and Snow Evolution Network (CanSISE) Climate Change and Atmospheric Research (CCAR) Network project (https: //www.cansise.ca/, last access: 24 April 2019). The input data for the historical period, i.e. 1950-2005, as well as the future (2006-2100) RCP simulations of CanRCM4 were provided by the parent ESM (CanESM2) as specified in the Coupled Model Intercomparison Project Phase 5 (CMIP5) guidelines. The data are sourced from the Canadian Centre for Climate Modelling and Analysis (CCCma) at: http: //www.cccma.ec.gc.ca/data/canrcm/CanRCM4 (last access: 6 March 2019). This study utilized 15 members of the $0.44^{\circ}$ resolution product at $1 \mathrm{~h}$ time step and values were aggregated to $3 \mathrm{~h}$ resolution prior to bias correction. The seven forcing variables needed for driving the CCRN MESH model (https://wiki.usask.ca/display/MESH/About+MESH, last access: 10 May 2019) and which were bias-corrected in the current study are included in Table 2.

\subsection{Data processing and bias correction workflow}

The workflow for the multistage bias correction of WFDEI against GEM-CaPA is shown in Fig. 3. Bias correction was done after aggregating $1 \mathrm{~h}$ GEM-CaPA estimates to $3 \mathrm{~h}$ (the

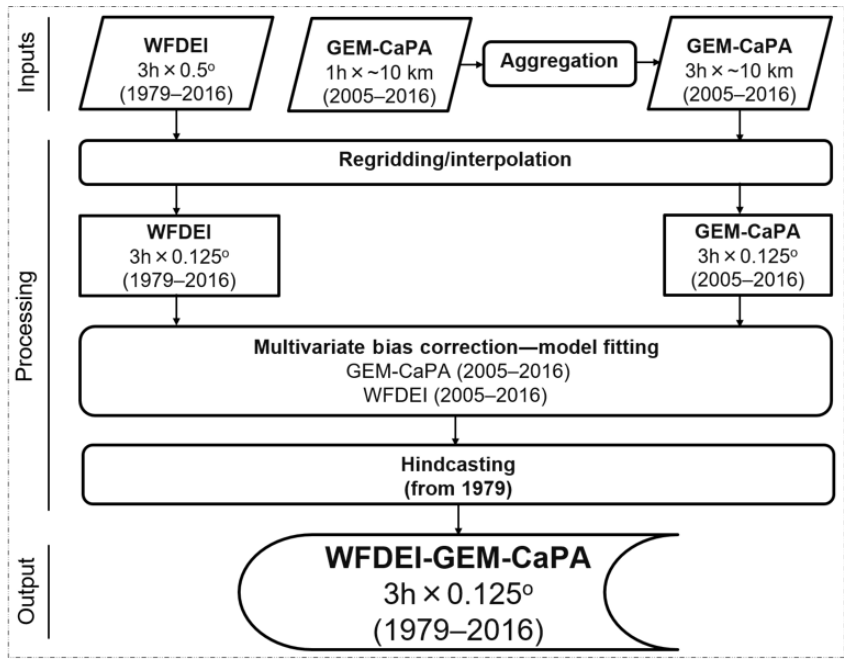

Figure 3. A schematic representation of inputs and the bias correction procedure used to produce the WFDEI-GEM-CaPA meteorological forcing dataset.

values at each time step represent the mean of the previous $3 \mathrm{~h}$ period, to make it consistent with WFDEI) and interpolating both WFDEI and GEM-CaPA to $0.125^{\circ}$ resolution. For bias correction, a multistage approach was implemented as follows. A multivariate generalization of the quantile mapping technique (MBCn, Cannon, 2018) which combines quantile delta mapping (Cannon et al., 2015) and random orthogonal rotations to match the multivariate distributions of two datasets was implemented to bias-correct WFDEI against GEM-CaPA at $3 \mathrm{~h} \times 0.125^{\circ}$ resolution during the 2005-2016 period. The rationale for selecting the above bias correction method is based on fitness for purpose; i.e. the method accounts for dependence between variables and corrects multiple measures of joint dependence attributes that can be important for hydrological simulations (Meyer et al., 2019) - to preserve the physical realism of the corrected climate as much as possible. Models were fitted to data for each calendar month while accounting for the inter-variable dependence structure. Using the fitted models (2005-2016), a hindcast was made of WFDEI between 1979 and 2004. Finally, the corrected WFDEI data derived from the fitted (2005-2016) and hindcast (1979-2004) periods were concatenated to obtain the bias-corrected WFDEIGEM-CaPA product (1979-2016).

For bias-correcting the 15-member CanRCM4 initial condition ensemble against the WFDEI-GEM-CaPA product, CanRCM4 was also spatially interpolated to match the WFDEI-GEM-CaPA specifications using nearest-neighbour interpolation. The multivariate bias correction technique (described above) transfers all aspects of the WFDEI-GEMCaPA continuous multivariate distribution to the corresponding multivariate distribution of variables from CanRCM4 during the 1979-2008 calibration period (also used here as 
Table 1. List of observation stations used for validating the various gridded historical products.

\begin{tabular}{llr|rr|r|r|r|rrrrr}
\hline & & Station & \multicolumn{2}{c}{ Coordinates } & & \multicolumn{2}{c}{ Record } & \multicolumn{4}{c}{ Percent complete } \\
\hline Name & Prov. & ID & Lat & Long & Elev. & Start & End & $T$ & $P$ & RH & ps & wind \\
\hline Jasper Warden & AB & 10223 & 52.93 & -118.03 & 1020.0 & 1994 & 2019 & 99.0 & 98.0 & 96.0 & 96.9 & 97.1 \\
Beaverlodge RCS & AB & 30669 & 55.20 & -119.40 & 745.0 & 2001 & 2019 & 99.0 & 93.9 & 93.8 & 93.9 & 93.8 \\
Barrhead CS & AB & 30641 & 54.09 & -114.45 & 648.0 & 2000 & 2019 & 98.2 & 98.1 & 97.8 & 97.8 & 97.0 \\
Lac La Biche climate & AB & 30726 & 54.77 & -112.02 & 567.0 & 2001 & 2019 & 99.0 & 98.8 & 97.8 & 97.9 & 97.9 \\
Uranium City (AUT) & SK & 9831 & 59.57 & -108.48 & 318.2 & 1992 & 2019 & 95.8 & 93.0 & 94.2 & 94.4 & 94.8 \\
Norman Wells climate & NT & 43004 & 65.29 & -126.75 & 93.6 & 2003 & 2019 & 98.5 & 96.6 & 96.0 & 95.4 & 96.2 \\
Fort Smith climate & NT & 41884 & 60.03 & -111.93 & 203.0 & 2003 & 2019 & 97.6 & 96.8 & 95.8 & 96.7 & 97.3 \\
Hay River climate & NT & 41885 & 60.84 & -115.78 & 164.0 & 2003 & 2019 & 99.6 & 99.3 & 98.4 & 98.4 & 98.0 \\
Fort Simpson climate & NT & 41944 & 61.76 & -121.24 & 168.0 & 2003 & 2019 & 97.5 & 99.5 & 96.1 & 96.2 & 98.2 \\
Inuvik climate & NT & 41883 & 68.32 & -133.52 & 103.0 & 2003 & 2019 & 99.6 & 95.1 & 98.3 & 98.4 & 97.0 \\
\hline
\end{tabular}

Table 2. List of variables processed in this study with heights and units in each dataset.

\begin{tabular}{|c|c|c|c|c|}
\hline \multirow[t]{2}{*}{ Variable } & \multirow[t]{2}{*}{ Unit } & \multicolumn{3}{|c|}{ Height } \\
\hline & & WFDEI & GEM-CaPA & WFDEI-GEM-CaPA \\
\hline Precipitation & $\mathrm{kg} \mathrm{m}^{-2} \mathrm{~s}^{-1}$ & Surface & Surface & Surface \\
\hline Air temperature & $\mathrm{K}$ & $2 \mathrm{~m}$ & $40 \mathrm{~m}$ & $40 \mathrm{~m}$ \\
\hline Specific humidity & $\mathrm{kg} \mathrm{kg}^{-1}$ & $2 \mathrm{~m}$ & $40 \mathrm{~m}$ & $40 \mathrm{~m}$ \\
\hline Wind speed & $\mathrm{ms}^{-1}$ & $10 \mathrm{~m}$ & $40 \mathrm{~m}$ & $40 \mathrm{~m}$ \\
\hline Surface pressure & $\mathrm{Pa}$ & Surface & Surface & Surface \\
\hline Downwelling shortwave radiation & $\mathrm{W} \mathrm{m}^{-2}$ & Surface & Surface & Surface \\
\hline Downwelling longwave radiation & $\mathrm{W} \mathrm{m}^{-2}$ & Surface & Surface & Surface \\
\hline
\end{tabular}

the historical period). Subsequently, when applied to future projections, changes in quantiles of each variable between the historical and future period are also preserved. Models were fitted to data for each calendar month and for each grid point while preserving the dependence structure among variables. The historical datasets used in the fitting procedure include WFDEI-GEM-CaPA (1979-2008) and CanRCM4 (1979-2008). Using the fitted models, quantiles of CanRCM4 output from 1950 to 2100 were changed. To evaluate the need to bias-correct CanRCM4, performance of the bias correction scheme, as well the impact of bias correction on the climate change signal, and the seasonal cycle of all seven variables is assessed over three 30-year periods: 19792008 (referred to hereafter as 1990s), 2021-2050 (referred to hereafter as 2030s), and 2071-2100 (referred to hereafter as 2080s).

\section{Results and discussion}

\subsection{Bias correction of WFDEI}

Table 2 presents an overview of the seven variables processed in this study. Note that three of the GEM variables (temperature, specific humidity, and wind speed) are at $40 \mathrm{~m}$ and are used directly to correct the corresponding WFDEI surface variables (see Table 2). Therefore, the corrected WFDEIGEM-CaPA data for those three variables reflect $40 \mathrm{~m}$ elevations above the surface. The spatial coverage of the WFDEIGEM-CaPA data is the same as the areal extent of the MRB (Figs. 1 and 2). The suitability of the bias correction algorithm to reproduce the observed seasonal cycle and interannual variability of the variables was assessed for the fitting (2005-2016) and hindcast (1979-2004) periods. Data extracted over the entire Mackenzie River Basin are used to demonstrate the quality of the bias correction exercise and uniqueness of the resulting output. Figure 4 shows the seasonal cycle for GEM-CaPA, WFDEI, and WFDEI-GEMCaPA during the fitting period. Overall, the monthly distributions show that the bias was removed for all variables resulting in the very close distributions between GEM-CaPA and WFDEI-GEM-CaPA. The bias was particularly large for wind speed, an important variable for both alpine and prairie blowing snow redistribution calculations (Pomeroy and $\mathrm{Li}, 2000$ ), but was successfully removed. Figure 5 shows the mean annual time series of the seven variables over the 1979-2016 period. It is noticeable that the bias is corrected while the inter-annual variability is well preserved between WFDEI and WFDEI-GEM-CAPA, except for shortwave radiation where the inter-annual variability is not fully preserved as shown by the correlation between the WFDEI and 

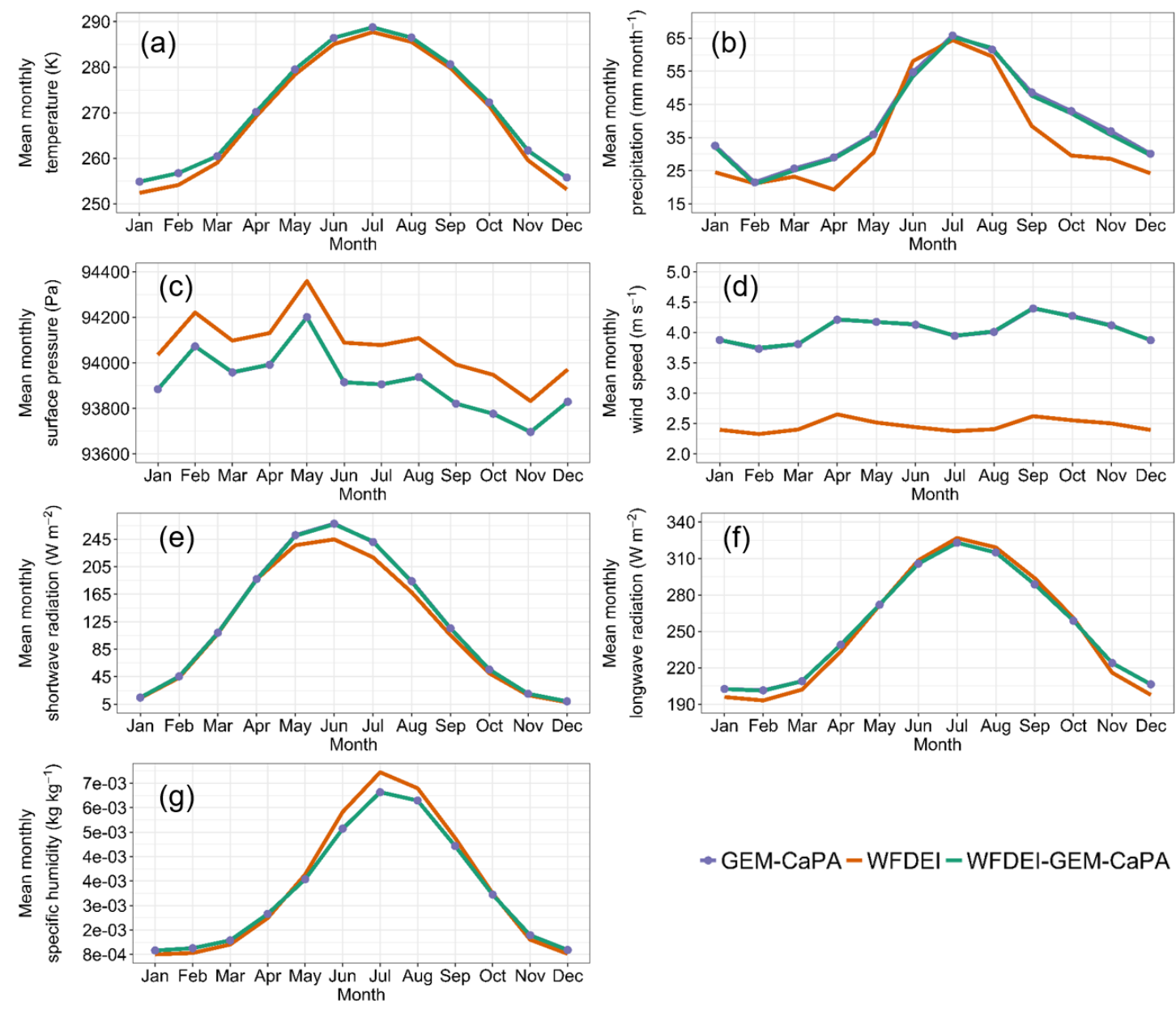

*GEM-CaPA - WFDEI-WFDEI-GEM-CaPA

Figure 4. Seasonal cycle of GEM-CaPA (dark slate blue), WFDEI (orange), and WFDEI-GEM-CaPA bias-corrected data (green) for air temperature (a), precipitation (b), surface pressure (c), wind speed (d), shortwave radiation (e), longwave radiation (f), and specific humidity (g) during the fitting period (2005-2016).

WFDEI-GEM-CaPA annual series. However, this should not be a major issue when impact models are driven using these data. The foregoing analyses have shown that the bias in the WFDEI data was removed for both the fitting and hindcast periods. However, some potential limitations remain - for example, WFDEI was interpolated directly from 0.5 to $0.125^{\circ}$ and bias-corrected against GEM-CaPA at $0.125^{\circ}$. The interpolation does not add any event-scale spatial variability for a variable like precipitation which is very variable across different scales. These issues have been reviewed extensively by Cannon (2018), Maraun (2013), Maraun et al. (2010), and Storch (1999).

\subsection{Validation of gridded products against station observations}

In this section, the WFDEI-GEM-CaPA product is validated against station observations (ECCC-S) to indicate the benefit of bias-correcting WFDEI against GEM-CaPA. As mentioned in Sect. 2.2.3, the validation focusses on variables for which station data could be found. Thus, shortwave and longwave radiation are not validated as we could not find station data for those in ECCC-S data. The height differences for temperature, humidity, and wind speed between GEM-CAPA and WFDEI-GEM-CaPA $(40 \mathrm{~m})$ on one side and ECCC-S data (surface) on the other introduce some inconsistencies that are discussed below. Indirect validation is recommended for other variables through other means such as hydrological modelling. Validation is performed for the 2005-2016 period using daily totals for precipitation and daily averages for other variables. To compare stations against gridded products, the corresponding time series of gridded products for each gauge were obtained from the cell that contained the gauge (i.e. nearest neighbour) and were aggregated to the daily timescale.

Figure 6 depicts quantile-quantile (Q-Q) plots of daily precipitation from WFDEI-GEM-CaPA, WFDEI, and GEMCaPA compared against ECCC-S. As expected, although with noticeable differences across the MRB, CaPA agrees 

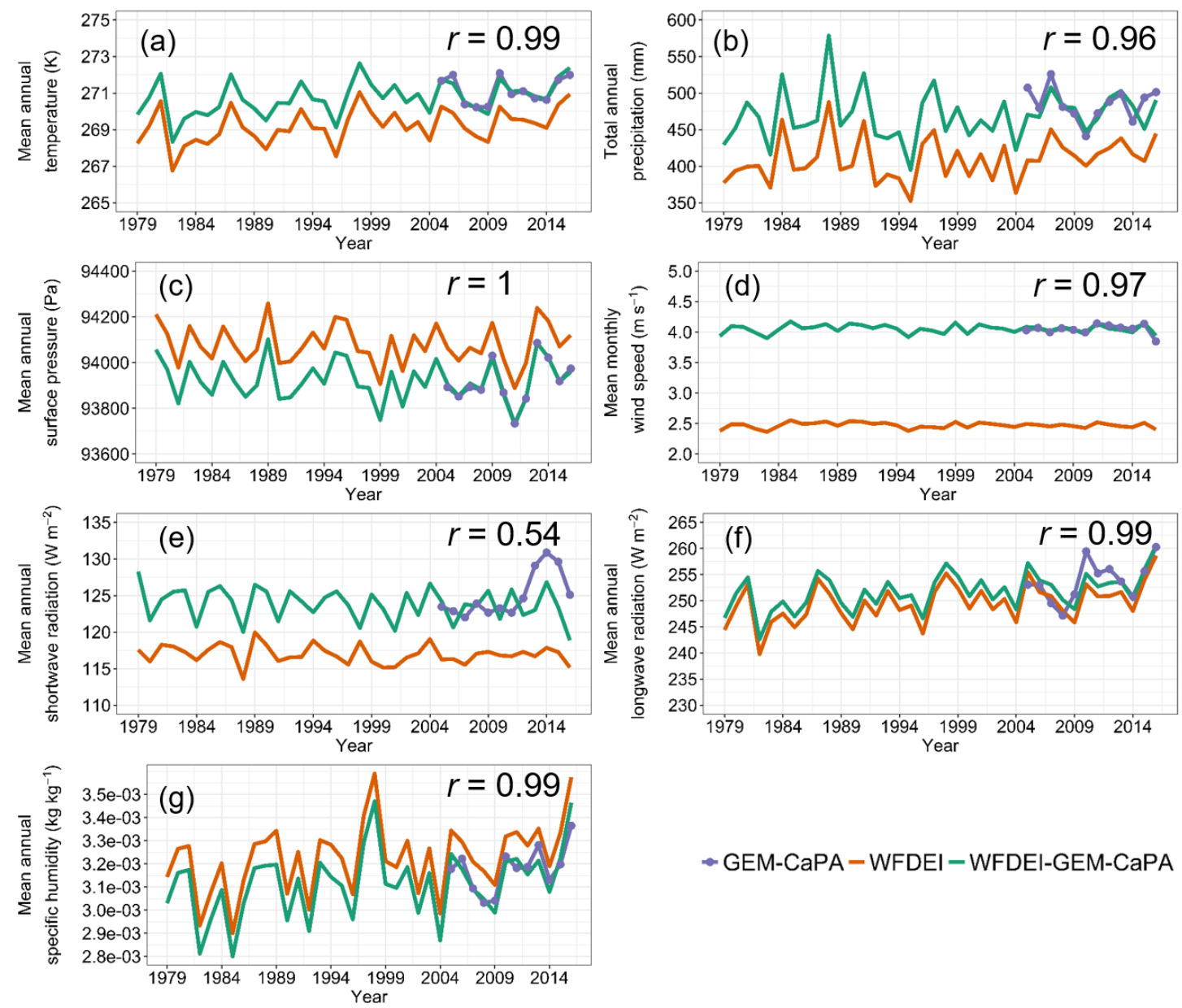

* GEM-CaPA - WFDEI - WFDEI-GEM-CaPA

Figure 5. Time series of GEM-CaPA (dark slate blue), WFDEI (orange), and WFDEI-GEM-CaPA bias-corrected data (green) for air temperature (a), precipitation (b), surface pressure (c), wind speed (d), shortwave radiation (e), longwave radiation (f), and specific humidity (g) during the periods 2005-2016 (GEM-CaPA) and 1979-2016 (WFDEI and WFDEI-GEM-CaPA). The correlation $(r)$ between the WFDEI and WFDEI-GEM-CaPA annual series is indicated for each variable.

better with ECCC-S than WFDEI since some or all of these meteorological stations are assimilated by the CaPA system. Large daily amounts are generally underestimated by CaPA, but CaPA sometimes overestimates these as well (e.g. Uranium City (AUT) station). WFDEI tends to underestimate the observed precipitation amounts at most stations except at Jasper Warden, where it slightly overestimates small and moderate amounts. Bias correction brings WFDEI closer to CaPA for most stations, but some biases remain, especially at the high ends of the distributions.

Figure 7 shows quantile-quantile plots of mean daily temperature for the three gridded datasets versus ECCC-S. WFDEI is performing generally well for temperature except for low temperatures at Inuvik (the most northerly station). Despite the height difference (see Sect. 2.2.3), GEM is also close to observations for most stations with some overestimation of low temperatures. The temperature differences between the surface and the $40 \mathrm{~m}$ level are generally small $\left(1-2^{\circ} \mathrm{C}\right)$ at the daily scale. Given that temperature biases in
WFDEI were small, WFDEI-GEM-CaPA is almost identical to GEM; i.e. all biases are removed.

Comparisons between gridded datasets and stations for daily mean surface pressure, wind speed, and humidity are shown in Figs. 8, 9, and 10 respectively. WFDEI generally performs well for surface pressure (Fig. 8) such that bias correction seems unnecessary at most locations. Both datasets (WFDEI and GEM) underestimate surface pressure at Jasper Warden station, which is at a relatively high elevation. GEM is worse than WFDEI for this station, and thus bias correction against GEM-CaPA deteriorates the results. WFDEI slightly underestimates surface pressure at Uranium City (AUT) and Norman Wells climate stations, but because GEM is close to observations, bias correction makes WFDEI-GEM-CaPA close to observations at those two stations.

Mean daily wind speed (Fig. 9) is underestimated by WFDEI for most stations, especially at high speeds. GEM winds are generally higher (except for Fort Simpson) because of the higher elevation $(40 \mathrm{~m})$ of the dataset, and thus the 


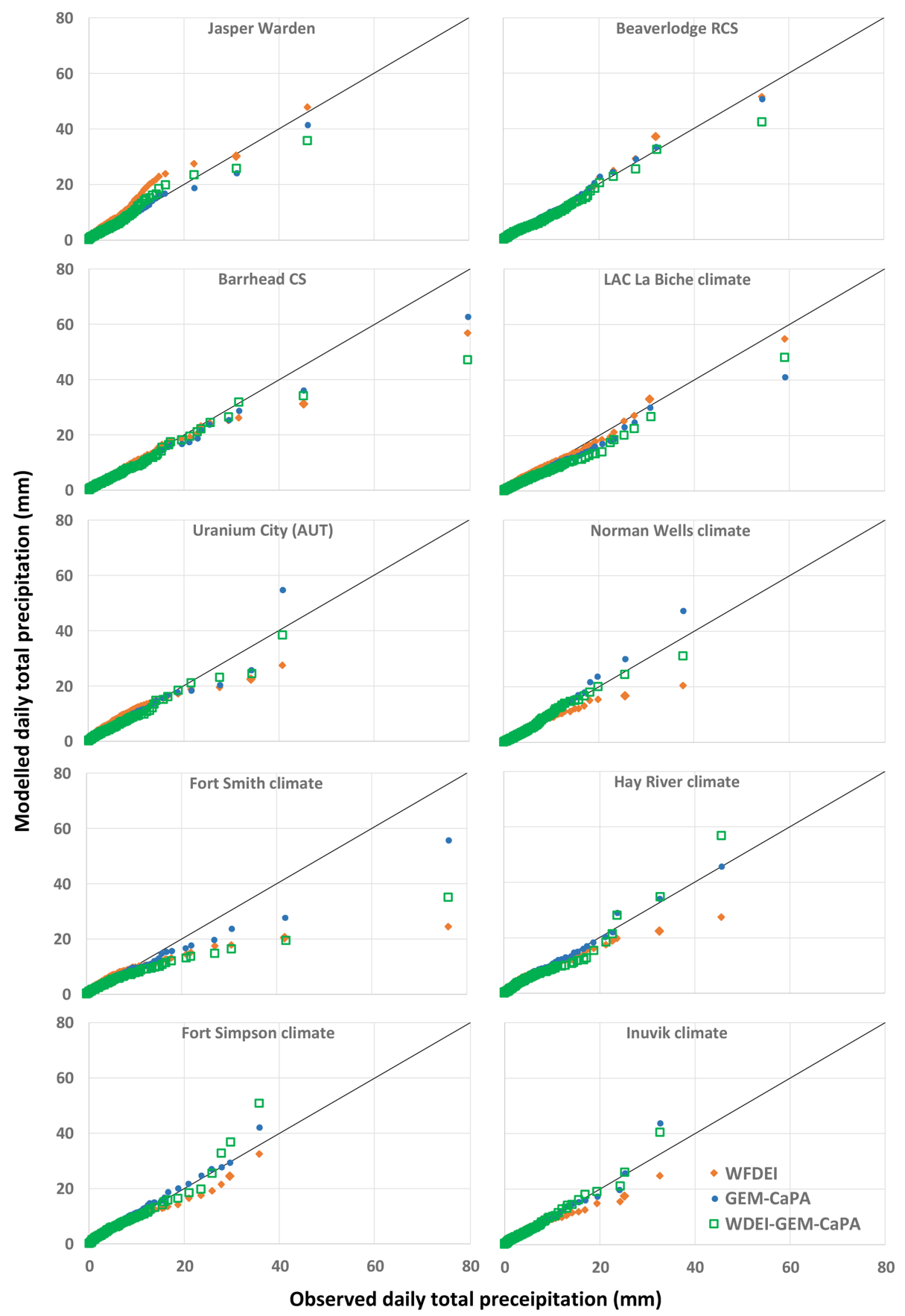

Figure 6. Quantile-quantile plots of modelled (GEM-CaPA, WFDEI, and WFDEI-GEM-CaPA) and observed (ECCC-S) daily total precipitation.

comparison to ECCC-S data is not favourable for this variable. It is generally expected that wind speed increases with height. Bias correction of WFDEI against GEM-CaPA removes differences between the two datasets, and the resultant wind speed, thus, reflects the higher speeds to be expected at $40 \mathrm{~m}$.

Both WFDEI and GEM are close in terms of specific humidity at most stations (Fig. 10) despite the height difference, with few exceptions. For example, humidity at the Jasper Warden, Barrhead CS, and Inuvik climate stations is underestimated by both WFDEI and GEM, especially at high values. Bias correction brings WFDEI closer to GEM and thus results in improvements only if GEM is closer to observations than WFDEI. Thus, results at Fort Smith climate and Inuvik climate stations are worse with bias correction. However, the 


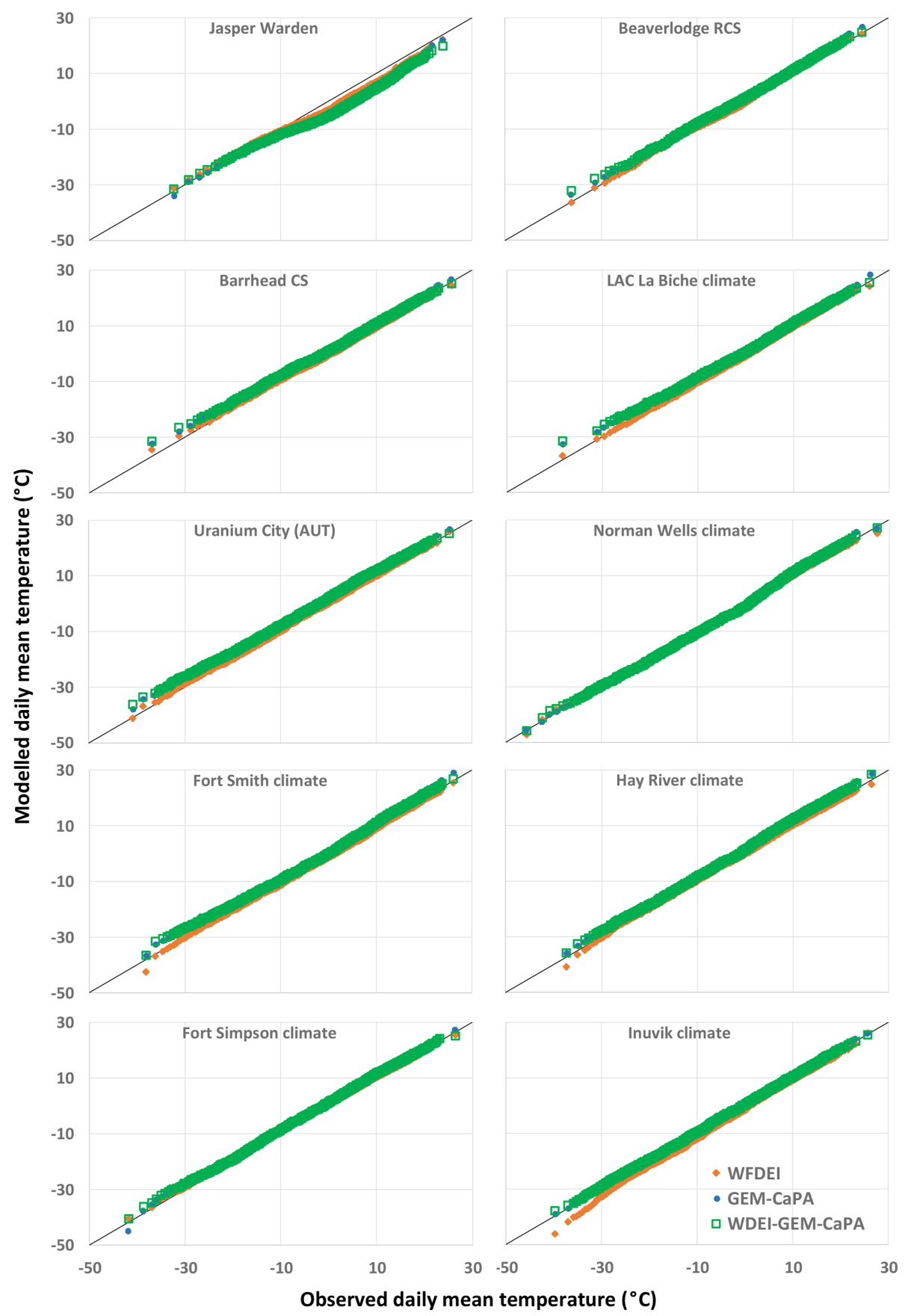

Figure 7. Quantile-quantile plots of modelled (GEM-CaPA, WFDEI, and WFDEI-GEM-CaPA) and observed (ECCC-S) daily mean temperature.

bias correction does not change the quantiles by much for most stations.

Overall, GEM-CaPA performs similar to or better than WFDEI for most variables at the studied stations, especially precipitation. Therefore, correcting WFDEI against GEM$\mathrm{CaPA}$ adds value to the WFDEI dataset and leads to a closer agreement between WFDEI-GEM-CaPA and ECCC-S. Precipitation is one of the most important variables and most difficult to correct. Note that extracting data from grid points does not only have the effect of smoothing the areal averages but comparing grid point estimates to station values may not provide a clear picture of the quality of a gridded product. However, this diagnostic analysis provides preliminary insights into the potential performance of a dataset. 


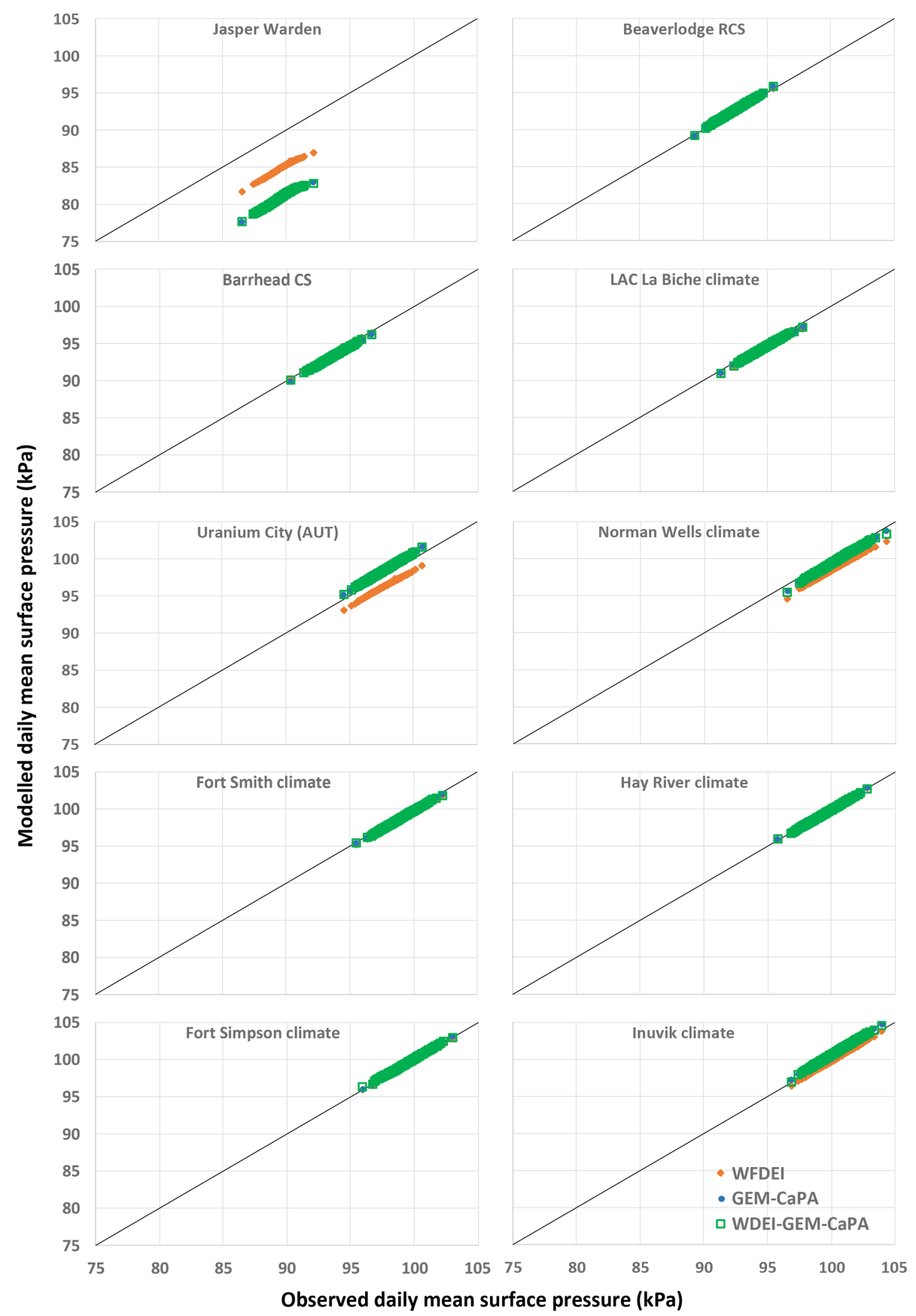

Figure 8. Quantile-quantile plots of modelled (GEM-CaPA, WFDEI, and WFDEI-GEM-CaPA) and observed daily mean surface pressure.

\subsection{Bias correction of future climate projections}

In this section, the need to bias-correct the CanRCM4 outputs is shown and whether the simulated climate change signal was preserved after applying MBCn to the CanRCM4 outputs is determined. Figure 11 shows the climatological seasonal cycle of all seven variables which are required to drive the MESH model for the MRB. First, between April and October, CanRCM4 overestimates the observed (i.e. WFDEIGEM-CaPA) daily precipitation amounts and specific hu- midity during the historical period. This is also true in the case of daily mean wind speed in the cold months (October to April). However, it underestimates the wind speed in the warm season (May to September). Surface pressure is underestimated during September to May and overestimated in the summer (June to August). For the other variables (e.g. air temperature and radiation), CanRCM4 can simulate the observed seasonal cycle closely, although biases still exist. These biases necessitated the application of the MBCn algo- 


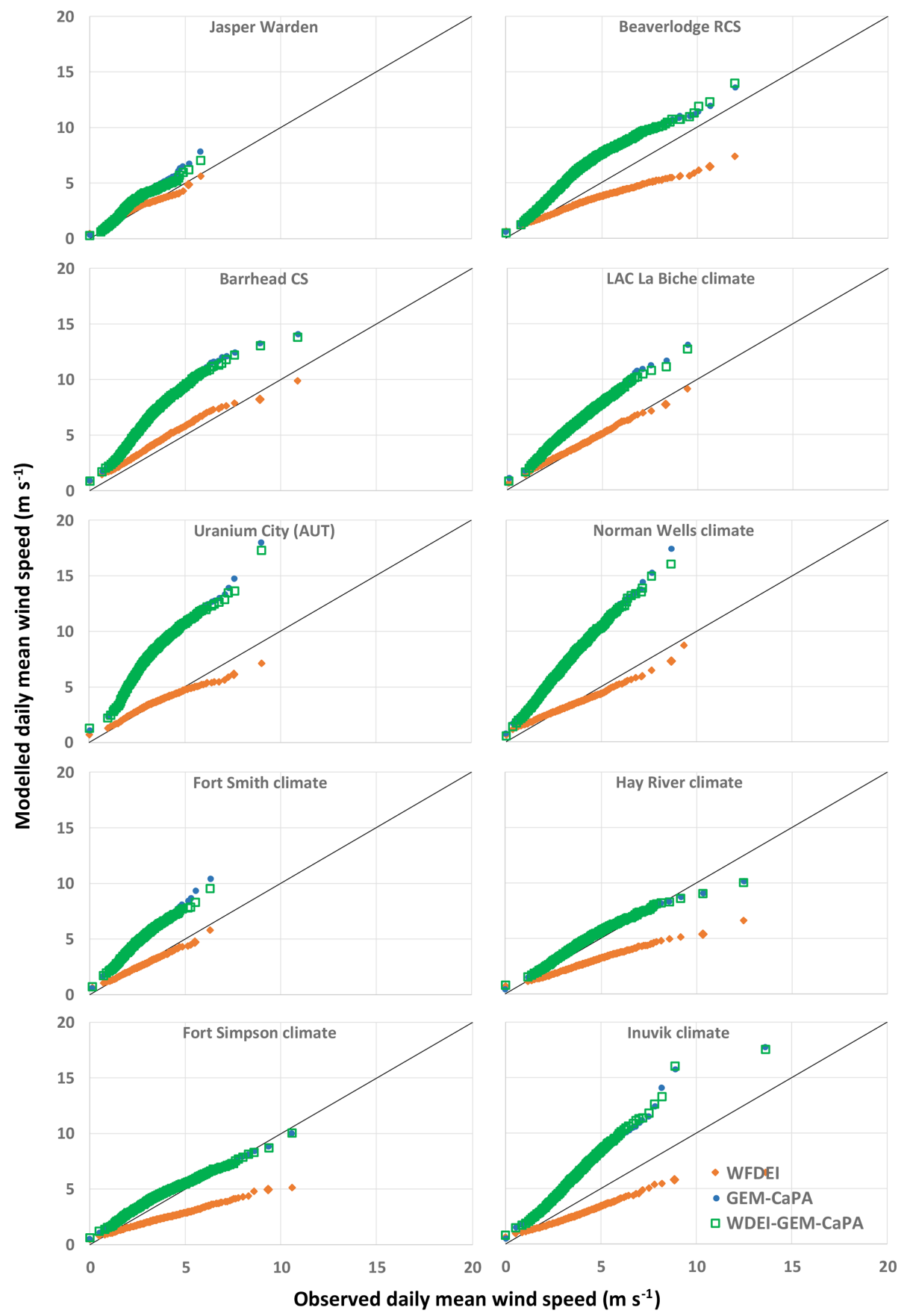

Figure 9. Quantile-quantile plots of modelled (GEM-CaPA, WFDEI, and WFDEI-GEM-CaPA) and observed daily mean wind speed.

rithm on the raw CanRCM4 outputs. The MBCn algorithm removed the bias in the CanRCM4 simulations during the fitting period (1990s) as can be judged from the close fit between WFDEI-GEM-CaPA and the unbiased CanRCM4 output (corr_1990s). On the projected climate change signal, there is a projected change in the amplitude of all variables but not a shift in the phase of the cycle over the MRB with global warming. Precipitation, specific humidity, and longwave radiation are projected to increase in the future, with larger changes expected in the warm season (April-October), while air temperature is projected to increase, particularly in the cold months (October-March). These climate change signals are very well preserved after applying $\mathrm{MBCn}$ to the CanRCM4 simulations. 


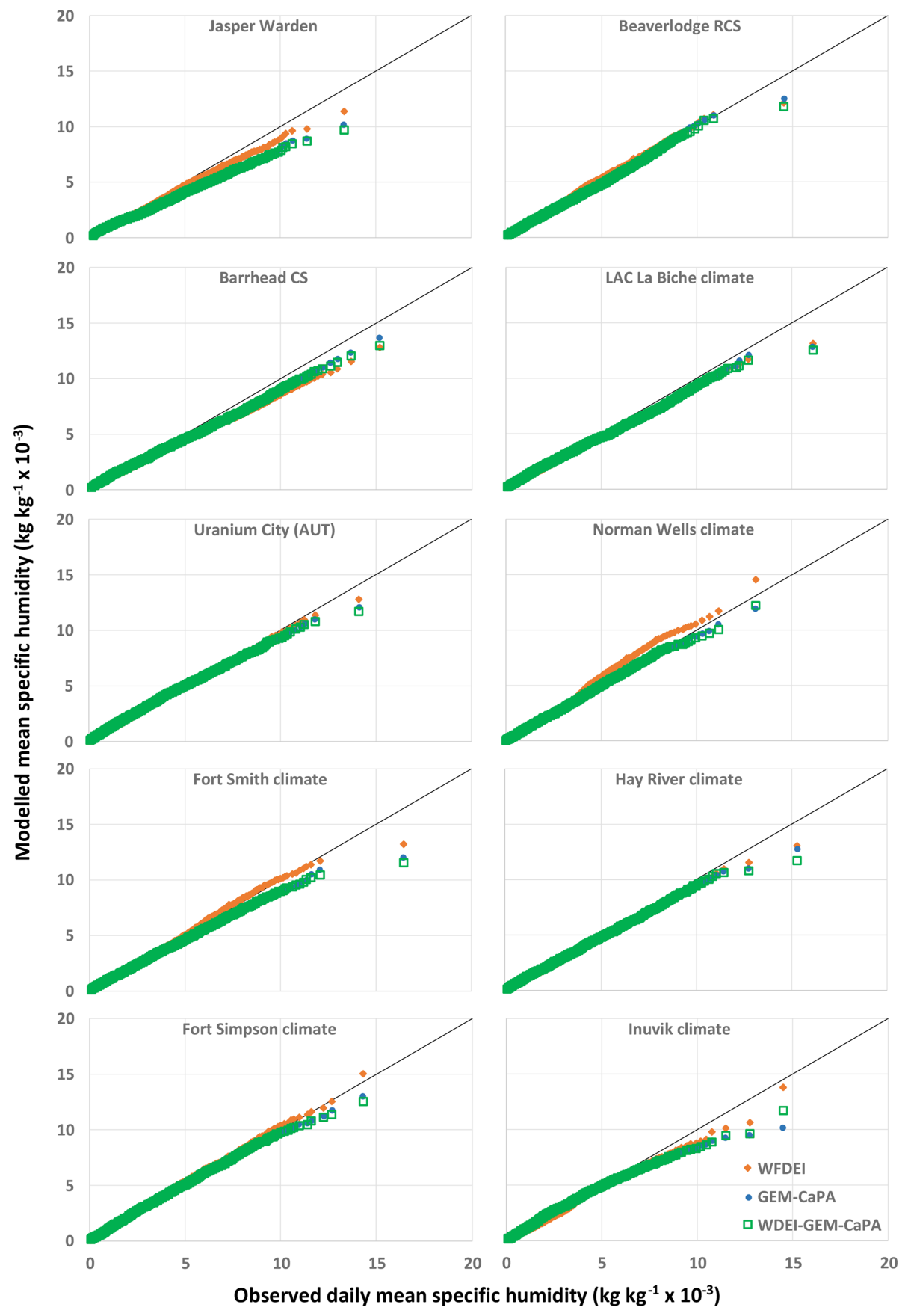

Figure 10. Quantile-quantile plots of modelled (GEM-CaPA, WFDEI, and WFDEI-GEM-CaPA) and observed daily specific humidity.

\section{Data availability}

The final product (WFDEI-GEM-CaPA, 1979-2016) is freely available at the Federated Research Data Repository at https://doi.org/10.20383/101.0111 (Asong et al., 2018), while the original (raw) and corrected CanRCM4 data are also freely available at https://doi.org/10.20383/101.0162 (Asong et al., 2019).

\section{Conclusions}

Cold region hydrology is very sensitive to the impacts of climate warming. More physically realistic hydrological models need to be driven by reliable climate forcing and can provide the capability to assess hydrological responses to climate variability and change. However, cold regions such as the Mackenzie River Basin often have sparse surface observations, particularly at high elevations and latitudes where a 

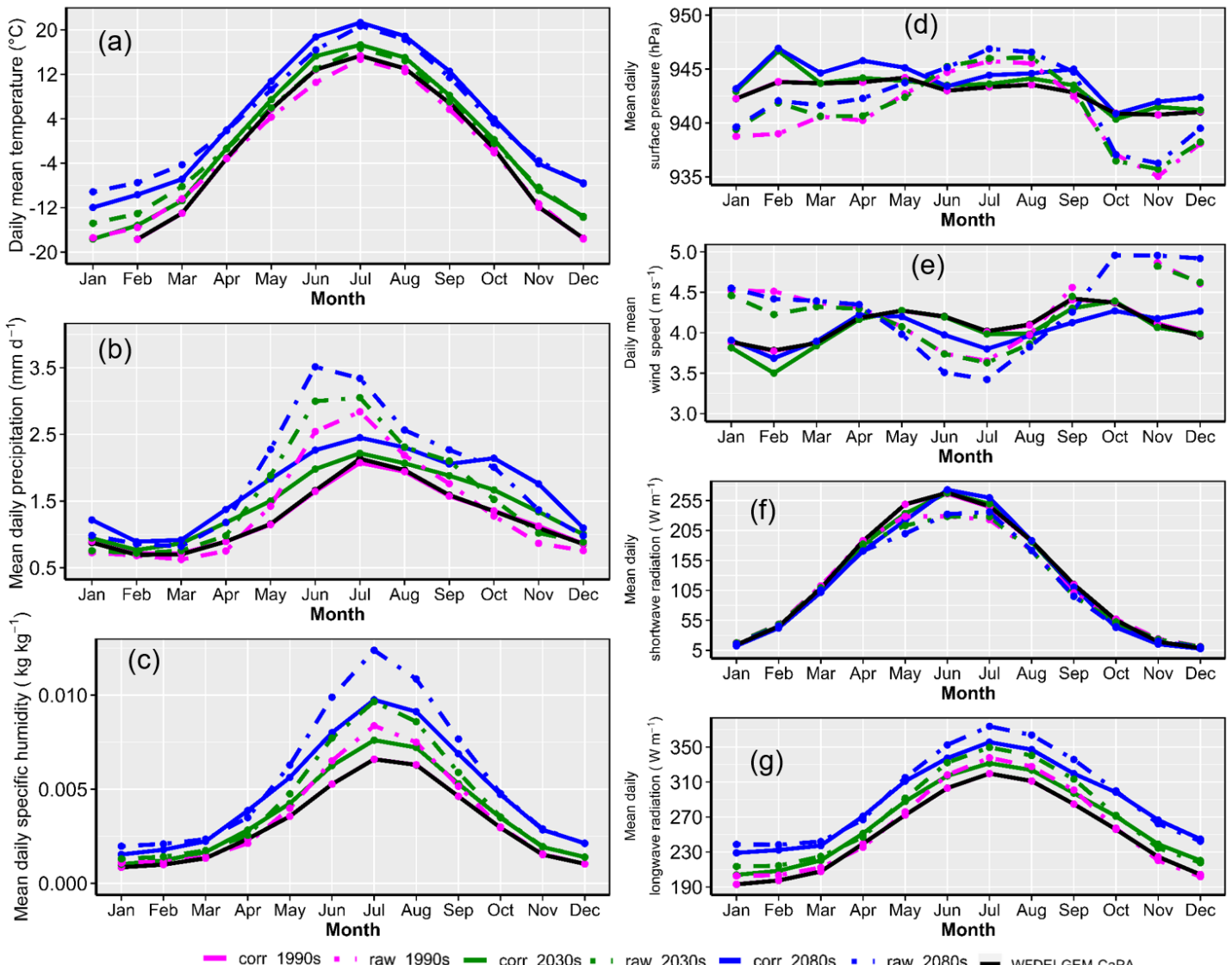

Figure 11. Seasonal cycle of WFDEI-GEM-CaPA, raw, and bias-corrected CanRCM4 data for air temperature (a), precipitation (b), specific humidity (c), surface pressure (d), wind speed (e), shortwave radiation (f), and longwave radiation (g) during the periods 1979-2008, 20212050, and 2071-2100.

large amount of runoff is generated or important cryosphere processes are impacting the hydrology. A novel approach to developing a long-term dataset using the WFDEI-GEM$\mathrm{CaPA}$ approach outlined above was necessary to better understand and represent the seasonal/inter-annual variability of hydrological fluxes and the timing of runoff, as well as their long-term trends. This dataset is also valuable for bias correction of climate model projections to assess potential impacts of future climate change on the hydrology and water resources of the basin.

The raw CanRCM4 outputs were found to have systematic biases, which required bias correction towards WFDEIGEM-CaPA. There are clear discrepancies between the seasonal cycle of WFDEI-GEM-CaPA, raw, and bias-corrected CanRCM4 data. For example, the CanRCM4-simulated climatological daily mean precipitation in June over the MRB between 1979 and 2008 is $\sim 2.5 \mathrm{~mm} \mathrm{~d}^{-1}$ while the observed value is $\sim 1.5 \mathrm{~mm} \mathrm{~d}^{-1}$. This results in a $1.0 \mathrm{~mm} \mathrm{~d}^{-1}$ wet bias which can have various implications for quantifying water resource availability, management, and adaptation in a future changed climate. Therefore, it was crucial to produce the bias-corrected CanRCM4 outputs prior to using the data to drive large-scale hydrological models for climate change impact analysis in the MRB. Nevertheless, the WFDEI-GEM$\mathrm{CaPA}$ dataset, used here as the reference, has uncertainties (although it is superior to WFDEI as shown in Figs. 6-11) and should be used with caution especially from the perspective of over-interpreting impact model outputs.

Supplement. The supplement related to this article is available online at: https://doi.org/10.5194/essd-12-629-2020-supplement.

Author contributions. ZEA, HSW, JWP, AP, and MEE conceived and designed the experiment. DP preprocessed the GEM$\mathrm{CaPA}$ data, AC developed the bias correction model code and guided the computing procedures, and ZEA performed the computations. MEE extracted the sample data used in generating Figs. 4 and 5. MEE and ZEA performed the validation against station observations. ZEA and MEE prepared the paper with contributions from all co-authors. 
Competing interests. The authors declare that they have no conflict of interest.

Acknowledgements. Financial support from the Canada Excellence Research Chair in Water Security, the NSERC Changing Cold Regions Network, and the Global Water Futures programme is gratefully acknowledged. Thanks are due to the Meteorological Service of Canada for providing access to the GEM-CaPA data used in this study. We also thank Graham Weedon for making available the WFDEI dataset. We also appreciate the efforts of Amber Peterson, Data Manager, Global Institute for Water Security, toward archiving the data at the Federated Research Data Repository.

Financial support. This research has been supported by the Canada First Research Excellence Fund (Global Water Futures programme), the Natural Sciences and Engineering Research Council of Canada (Changing Cold Regions Network), and the Canada Excellence Research Chairs (Water Security).

Review statement. This paper was edited by Prasad Gogineni and reviewed by two anonymous referees.

\section{References}

Alavi, N., Bélair, S., Fortin, V., Zhang, S., Husain, S. Z., Carrera, M. L., and Abrahamowicz, M.: Warm Season Evaluation of Soil Moisture Prediction in the Soil, Vegetation, and Snow (SVS) Scheme, J. Hydrometeorol., 17, 2315-2332, 2016.

Asong, Z. E., Khaliq, M. N., and Wheater, H. S.: Projected changes in precipitation and temperature over the Canadian Prairie Provinces using the Generalized Linear Model statistical downscaling approach, J. Hydrol., 539, 429-446, 2016 b.

Asong, Z. E., Razavi, S., Wheater, H. S., and Wong, J. S.: Evaluation of Integrated Multi-satellitE Retrievals for GPM (IMERG) over Southern Canada against Ground Precipitation Observations: A Preliminary Assessment, J. Hydrometeor., 18, 10331050, https://doi.org/10.1175/JHM-D-16-0187.1, 2017.

Asong, Z. E., Wheater, H., Pomeroy, J., Pietroniro, A., and Elshamy, M.: A Bias-Corrected 3-hourly 0.125 Gridded Meteorological Forcing Data Set (1979-2016) for Land Surface Modeling in North America, https://doi.org/10.20383/101.0111, 2018.

Asong, Z. E., Wheater, H., Pomeroy, J., Pietroniro, A., Elshamy, M., Princz, D., and Cannon, A.: High-Resolution Meteorological Forcing Data for Hydrological Modelling and Climate Change Impact Analysis in Mackenzie River Basin, https://doi.org/10.20383/101.0162, 2019.

Barnett, T. P., Adam, J. C., and Lettenmaier, D. P.: Potential impacts of a warming climate on water availability in snow-dominated regions, Nature, 438, 303-309, https://doi.org/10.1038/nature04141, 2005.

Behnke, R., Vavrus, S., Allstadt, A., Albright, T., Thogmartin, W. E., and Radeloff, V. C.: Evaluation of downscaled, gridded climate data for the conterminous United States, Ecol. Appl., 26, 1338-1351, 2016.
Beniston, M.: Climatic change in mountain regions: a review of possible impacts, in: Climate variability and change in high elevation regions: Past, present \& future, Springer, 2003.

Boluwade, A., Zhao, K. Y., Stadnyk, T. A., and Rasmussen, P.: Towards validation of the Canadian precipitation analysis (CaPA) for hydrologic modeling applications in the Canadian Prairies, J. Hydrol., 556, 1244-1255, 2018.

Brody, S. D., Zahran, S., Maghelal, P., Grover, H., and Highfield, W. E.: The Rising Costs of Floods: Examining the Impact of Planning and Development Decisions on Property Damage in Florida, J. Am. Plann. Assoc., 73, 330-345, 2007.

Cannon, A. J.: Multivariate quantile mapping bias correction: an Ndimensional probability density function transform for climate model simulations of multiple variables, Clim. Dynam., 50, 3149, 2018

Cannon, A. J., Sobie, S. R., and Murdock, T. Q.: Bias Correction of GCM Precipitation by Quantile Mapping: How Well Do Methods Preserve Changes in Quantiles and Extremes?, J. Climate, 28, 6938-6959, 2015.

Chadburn, S. E., Burke, E. J., Essery, R. L. H., Boike, J., Langer, M., Heikenfeld, M., Cox, P. M., and Friedlingstein, P.: Impact of model developments on present and future simulations of permafrost in a global land-surface model, The Cryosphere, 9, 1505-1521, https://doi.org/10.5194/tc-9-1505-2015, 2015.

Chen, J., Brissette, F. P., Chaumont, D., and Braun, M.: Finding appropriate bias correction methods in downscaling precipitation for hydrologic impact studies over North America, Water Resour. Res., 49, 4187-4205, 2013.

Chen, J., Li, C., Brissette, F. P., Chen, H., Wang, M., and Essou, G. R. C.: Impacts of correcting the inter-variable correlation of climate model outputs on hydrological modeling, J. Hydrol., 560, 326-341, 2018.

Coopersmith, E. J., Minsker, B. S., and Sivapalan, M.: Patterns of regional hydroclimatic shifts: An analysis of changing hydrologic regimes, Water Resour. Res., 50, 1960-1983, 2014.

DeBeer, C. M., Wheater, H. S., Carey, S. K., and Chun, K. P.: Recent climatic, cryospheric, and hydrological changes over the interior of western Canada: a review and synthesis, Hydrol. Earth Syst. Sci., 20, 1573-1598, https://doi.org/10.5194/hess-20-1573-2016, 2016.

Demaria, E. M. C., Roundy, J. K., Wi, S., and Palmer, R. N.: The Effects of Climate Change on Seasonal Snowpack and the Hydrology of the Northeastern and Upper Midwest United States, J. Climate, 29, 6527-6541, 2016.

Dibike, Y., Prowse, T., Bonsal, B., and O'Neil, H.: Implications of future climate on water availability in the western Canadian river basins, Int. J. Climatol., 37, 3247-3263, https://doi.org/10.1002/joc.4912, 2016.

Diffenbaugh, N. S., Scherer, M., and Ashfaq, M.: Response of snow-dependent hydrologic extremes to continued global warming, Nat. Clim. Change, 3, 379-384, https://doi.org/10.1038/nclimate1732, 2012.

Dumanski, S., Pomeroy, J. W., and Westbrook, C. J.: Hydrological regime changes in a Canadian Prairie basin, Hydrol. Process., 29, 3893-3904, 2015.

Eum, H.-I., Dibike, Y., Prowse, T., and Bonsal, B.: Inter-comparison of high-resolution gridded climate data sets and their implication on hydrological model simulation over the Athabasca Watershed, Canada, Hydrol. Process., 28, 4250-4271, 2014. 
Fang, X., Pomeroy, J. W., Ellis, C. R., MacDonald, M. K., DeBeer, C. M., and Brown, T.: Multi-variable evaluation of hydrological model predictions for a headwater basin in the Canadian Rocky Mountains, Hydrol. Earth Syst. Sci., 17, 1635-1659, https://doi.org/10.5194/hess-17-1635-2013, 2013.

Fortin, V., Jean, M., Brown, R., and Payette, S.: Predicting snow depth in a forest-tundra landscape using a conceptual model allowing for snow redistribution and constrained by observations from a digital camera, Atmos.-Ocean, 53, 200-211, 2015a.

Fortin, V., Roy, G., Donaldson, N., and Mahidjiba, A.: Assimilation of radar quantitative precipitation estimations in the Canadian Precipitation Analysis (CaPA), J. Hydrol., 531, 296-307, $2015 b$.

Gbambie, A. S. B., Poulin, A., Boucher, M.-A., and Arsenault, R.: Added Value of Alternative Information in Interpolated Precipitation Datasets for Hydrology, J. Hydrometeorol., 18, 247-264, 2017.

Gudmundsson, L., Bremnes, J. B., Haugen, J. E., and EngenSkaugen, T.: Technical Note: Downscaling RCM precipitation to the station scale using statistical transformations - a comparison of methods, Hydrol. Earth Syst. Sci., 16, 3383-3390, https://doi.org/10.5194/hess-16-3383-2012, 2012.

Hou, A. Y., Kakar, R. A., Neeck, S., Azarbarzin, A. A., Kummerow, C. D., Kojima, M., Oki, R., Nakamura, K., and Iguchi, T.: The Global Precipitation Measurement Mission, B. Ame. Meteorol. Soc., 95, 701-722, 2014.

IPCC: Climate Change 2013: The Physical Science Basis. Contribution of Working Group I to the Fifth Assessment Report of the Intergovernmental Panel on Climate Change, Cambridge University Press, Cambridge, United Kingdom and New York, NY, USA, 2013.

Islam, S. U., Déry, S. J., and Werner, A. T.: Future Climate Change Impacts on Snow and Water Resources of the Fraser River Basin, British Columbia, J. Hydrometeorol., 18, 473-496, 2017.

Kane, D. L., Hinzman, L. D., Woo, M.-K., and Everett, K. R.: Arctic hydrology and climate change, in: Arctic ecosystems in a changing climate, Elsevier, 1991.

Mahfouf, J. F., Brasnett, B., and Gagnon, S.: A Canadian precipitation analysis (CaPA) project: Description and preliminary results, Atmos.-Ocean, 45, 1-17, 2007.

Maraun, D.: Bias Correcting Climate Change Simulations - a Critical Review, Current Climate Change Reports, 2, 211-220, 2016.

Maraun, D.: Bias Correction, Quantile Mapping, and Downscaling: Revisiting the Inflation Issue, J. Climate, 26, 2137-2143, 2013.

Maraun, D., Shepherd, T. G., Widmann, M., Zappa, G., Walton, D., Gutiérrez, J. M., Hagemann, S., Richter, I., Soares, P. M. M., Hall, A., and Mearns, L. O.: Towards process-informed bias correction of climate change simulations, Nat. Clim. Change, 7, 764-773, https://doi.org/10.1038/nclimate3418, 2017.

Maraun, D., Wetterhall, F., Ireson, A. M., Chandler, R. E., Kendon, E. J., Widmann, M., Brienen, S., Rust, H. W., Sauter, T., Themeßl, M., Venema, V. K. C., Chun, K. P., Goodess, C. M., Jones, R. G., Onof, C., Vrac, M., and Thiele-Eich, I.: Precipitation downscaling under climate change: Recent developments to bridge the gap between dynamical models and the end user, Rev. Geophys., 48, RG3003, https://doi.org/10.1029/2009RG000314, 2010.

Martin, E. and Etchevers, P.: Impact of Climatic Changes on Snow Cover and Snow Hydrology in the French Alps, in: Global
Change and Mountain Regions: An Overview of Current Knowledge, edited by: Huber, U. M., Bugmann, H. K. M., and Reasoner, M. A., Springer Netherlands, Dordrecht, 2005.

Meyer, J., Kohn, I., Stahl, K., Hakala, K., Seibert, J., and Cannon, A. J.: Effects of univariate and multivariate bias correction on hydrological impact projections in alpine catchments, Hydrol. Earth Syst. Sci., 23, 1339-1354, https://doi.org/10.5194/hess-231339-2019, 2019.

Milly, P. C. D., Betancourt, J., Falkenmark, M., Hirsch, R. M., Kundzewicz, Z. W., Lettenmaier, D. P., and Stouffer, R. J.: Stationarity Is Dead: Whither Water Management, Science, 319, 573-574, 2008.

Park, H., Yoshikawa, Y., Oshima, K., Kim, Y., Ngo-Duc, T., Kimball, J. S., and Yang, D.: Quantification of Warming ClimateInduced Changes in Terrestrial Arctic River Ice Thickness and Phenology, J. Climate, 29, 1733-1754, 2016.

Pomeroy, J. W. and Li, L.: Prairie and arctic areal snow cover mass balance using a blowing snow model, J. Geophys. Res.-Atmos., 105, 26619-26634, 2000.

Prowse, T. D. and Beltaos, S.: Climatic control of river-ice hydrology: a review, Hydrol. Process., 16, 805-822, 2002.

Reiter, P., Gutjahr, O., Schefczyk, L., Heinemann, G., and Casper, M.: Bias correction of ENSEMBLES precipitation data with focus on the effect of the length of the calibration period, Meteorol. Z., 25, 85-96, 2016.

Sapiano, M. R. P. and Arkin, P. A.: An Intercomparison and Validation of High-Resolution Satellite Precipitation Estimates with 3-Hourly Gauge Data, J. Hydrometeorol., 10, 149-166, 2009.

Schoetter, R., Hoffmann, P., Rechid, D., and Schlünzen, K. H.: Evaluation and Bias Correction of Regional Climate Model Results Using Model Evaluation Measures, J. Appl. Meteorol. Clim., 51, 1670-1684, 2012.

Schulzweida, U., Kornblueh, L., and Quast, R.: Climate data operators, Max-Planck-Institute for Meteorology, Hamburg, available at: http://www.mpimet.mpg.de/ cdo (last access: 29 May 2019), 2004.

Sheffield, J., Goteti, G., and Wood, E. F.: Development of a 50-Year High-Resolution Global Dataset of Meteorological Forcings for Land Surface Modeling, J. Climate, 19, 3088-3111, 2006.

Sippel, S., Otto, F. E. L., Forkel, M., Allen, M. R., Guillod, B. P., Heimann, M., Reichstein, M., Seneviratne, S. I., Thonicke, K., and Mahecha, M. D.: A novel bias correction methodology for climate impact simulations, Earth Syst. Dynam., 7, 71-88, https://doi.org/10.5194/esd-7-71-2016, 2016.

Stocker, T. F., Qin, D., Plattner, G.-K., Alexander, L. V., Allen, S. K., Bindoff, N. L., Breìon, F.-M., Church, J. A., Cubasch, U., Emori, S., Forster, P., Friedlingstein, P., Gillett, N., Gregory, J. M., Hartmann, D. L., Jansen, E., Kirtman, B., Knutti, R., Krishna Kumar, K., Lemke, P., Marotzke, J., Masson-Delmotte, V., Meehl, G. A., Mokhov, I. I., Piao, S., Ramaswamy, V., Randall, D., Rhein, M., Rojas, M., Sabine, C., Shindell, D., Talley, L. D., Vaughan, D. G., and Xie, S.-P.: Technical Summary, in: Climate Change 2013: The Physical Science Basis. Contribution of Working Group I to the Fifth Assessment Report of the Intergovernmental Panel on Climate Change, edited by: Stocker, T. F., Qin, D., Plattner, G.-K., Tignor, M., Allen, S. K., Boschung, J., Nauels, A., Xia, Y., Bex, V., and Midgley, P. M., Cambridge University Press, Cambridge, United Kingdom and New York, NY, USA, 2013. 
Storch, H. V.: On the Use of "Inflation" in Statistical Downscaling, J. Climate, 12, 3505-3506, 1999.

Taylor, K. E., Stouffer, R. J., and Meehl, G. A.: An Overview of CMIP5 and the Experiment Design, B. Ame. Meteorol. Soc., 93, 485-498, 2012.

Vincent, L. A., Zhang, X., Brown, R. D., Feng, Y., Mekis, E., Milewska, E. J., Wan, H., and Wang, X. L.: Observed Trends in Canada's Climate and Influence of Low-Frequency Variability Modes, J. Climate, 28, 4545-4560, 2015.

Wang, X. L. and Lin, A.: An algorithm for integrating satellite precipitation estimates with in situ precipitation data on a pentad time scale, J. Geophys. Res.-Atmos., 120, 3728-3744, 2015.

Weedon, G. P., Balsamo, G., Bellouin, N., Gomes, S., Best, M. J., and Viterbo, P.: The WFDEI meteorological forcing data set: WATCH Forcing Data methodology applied to ERA-Interim reanalysis data, Water Resour. Res., 50, 7505-7514, 2014.
Wong, J. S., Razavi, S., Bonsal, B. R., Wheater, H. S., and Asong, Z. E.: Inter-comparison of daily precipitation products for largescale hydro-climatic applications over Canada, Hydrol. Earth Syst. Sci., 21, 2163-2185, https://doi.org/10.5194/hess-21-21632017, 2017.

Woo, M.-K. and Pomeroy, J.: Snow and Runoff: Processes, Sensitivity and Vulnerability, in: Changing Cold Environments, John Wiley \& Sons, Ltd, 2011.

Yeh, K.-S., Côté, J., Gravel, S., Méthot, A., Patoine, A., Roch, M., and Staniforth, A.: The CMC-MRB Global Environmental Multiscale (GEM) Model. Part III: Nonhydrostatic Formulation, Mon. Weather Rev., 130, 339-356, 2002. 